\title{
A CLASSIFICATION OF LEPROSY FOR RESEARCH PURPOSES
}

\author{
By D. S. RIDLEY and W. H. JOPLING \\ (Hospital for Tropical Diseases, London and Jordan Hospital, \\ Earlswood, Surrey, England)
}

Accepted systems of classifying leprosy, being based on the need to achieve the widest possible agreement and to serve a variety of purposes, do not provide the detail which is sometimes desired for research. This paper has the limited object of describing a classification which has been adopted for certain therapeutic trials and other projects. The scheme contains few important departures from accepted ideas.

It was assumed that, underlying the various differences between tuberculoid and lepromatous leprosy, the question of resistance by patient to infection was fundamental. The object of classification was to assess prognosis and expected response to treatment, which depend to a considerable extent on a patient's resistance. It was assumed further that every degree of resistance may on occasion be encountered; but for convenience an attempt was made to define 5 grades or groups by reference to the clinical, histological, bacteriological and immunological patterns which have been found by experience to have a bearing on a patient's resistance and prognosis.

The procedure therefore was to construct a skeleton scheme of classification in 5 groups (Table 1), the two "poles" of which were tuberculoid and lepromatous defined by the strictest orthodox criteria; and subsequently to determine the characteristics of the intervening groups by correlating various characteristics with the outcome of a follow-up study after treatment.

\section{Method}

For several years we had attempted to classify new patients at the Jordan Hospital as precisely as possible in the "spectrum" between tuberculoid and lepromatous and in due course the " 5 group TT-LL" classification evolved. The response to treatment was followed in several ways. Close clinical observation was supported by photographs. Bacteriological progress was assessed by routine serial biopsies (RIDLEY, 1958), using biopsies of 2 lesions every 6 months; large but representative lesions or areas of diffuse involvement, which provided a number of consecutive biopsies were selected; where the lesions were all small, comparable lesions suitable for future biopsy were marked on a chart. Skin smears also were examined. Recently a granularity index for bacilli was introduced but the 
results, being incomplete, are omitted from the analysis. Lepromin testing was undertaken as a routine. The various criteria we had used in classification were then evaluated in the light of the follow-up study. The analysis, based on 35 cases, was retrospective. In 1958 we were given the opportunity to examine a large group of new patients at Sungei Buloh Settlement, Malaya, and subsequently to observe the bacteriological progress of 47 suitable cases in the same manner as for the Jordan Hospital patients. It was thus possible to check our retrospective conclusions, and where necessary to revise them, in the light of a non-retrospective trial.

The patients at the Jordan Hospital were of many races, those at Sungei Buloh were predominently Chinese. All those with an initial biopsy index of 1.0 or more were accepted for a follow-up analysis. (The maximum score was $6.0 ; 1.0$ would be the score of a lesion occupying $1 / 5$ th of the dermis in which the bacterial index was $5+$ ). This qualification allowed the inclusion of an occasional BT case, the majority of BB cases and nearly all BL and LL cases. All the patients who were included in the analysis were on sulphone treatment except for 4 who received Ciba 1906. Reactions were disregarded in the bacteriological analysis unless they were sufficiently severe to cause an interruption of treatment for a month or more, or to cause an alteration in the patient's classification, in which case the patient was rejected from the analysis. All the 82 patients in the combined analysis were followed for at least 12 months, except for 6 (all BT or BB) in whom bacilli became too scanty to assess after 6 months; 35 were followed up for two years or more.

\section{Results}

Clinical classification. Clinically the characteristics of tuberculoid and lepromatous leprosy merge from one to the other through the intervening sub-divisions. Clinical classification therefore was based on an estimate of the general trend or pattern of the lesions. It was possible to judge the value of this classification by the subsequent course of the infection, but not to evaluate individual charactertisics on which it was based. The principal features of the clinical assessment were as follows.

Clinical features which differentiate borderline !eprosy from the lepromatous and tuberculoid types. Skin lesions of borderline leprosy are not as numerous or as small as in the lepromatous type nor as few or as large as in the tuberculoid type; their distribution is not as symmetrical on the two sides of the body as in the lepromatous type nor as markedly asymmetrical as in the tuberculoid type; their surface is not as smooth and shiny as in the lepromatous type nor as irregular and dry-looking as in the tuberculoid type; they have neither the absence of anaesthesia which is a feature of lepromatous 
leprosy nor the marked sensory loss of tuberculoid leprosy; macules and plaques have neither the vague and ill-defined edges characteristic of lepromatous lesions nor the sharp, clearly-defined edges of tuberculoid lesions.

Annular lesions are common in borderline leprosy and often take the form of a roughly oval area of hypopigmented skin surrounded by a slightly raised lesion which has a raised and well-defined inner edge, giving a punched-out appearance. In contrast, annular lesions are not a feature of lepromatous leprosy, and in tuberculoid leprosy they have raised and clear-cut outer borders with flattening towards the centre.

Palpable thickening of peripheral nerves, if present, may help in making a diagnosis of borderline leprosy, for the number of affected nerves is likely to be greater than in tuberculoid leprosy and they are less thick and irregular; their number and thickness is also likely to be more than in lepromatous leprosy with a comparable length of history. Additional points of distinction from lepromatous leprosy are: the skin between lesions appears normal, not thickened (this applies especially to the face); there are no mucosal changes; the eyes are free from keratitis or iritis; the eyebrows are not deficient (unless a plaque is actually situated on part of an eyebrow); lymphadenopathy is not a feature of borderline leprosy.

Clinical features of lepromatous leprosy which has evolved from the borderline types. These patients have unmistakable evidence of lepromatous leprosy but careful examination reveals one or more of the following:

(1) One or more plaques or annular lesions possessing the characteristics of borderline lesions-see above.

(2) Peripheral nerve thickening in excess of that which would be expected in pure lepromatous leprosy with the same length of history, and not completely bilaterally symmetrical.

(3) Less involvement of eyes, mucosa and eyebrows than would be expected in pure lepromatous leprosy with a similar length of history.

These clinical criteria are summarized in Table 2.

Follow-up Study. The above clinical criteria were applied to patients both in England and in Malaya. In view of the distance separating the two groups of patients it was not possible to make a clinical comparison of progress under treatment. Progress was assessed by means of the biopsy index, which is a bacteriological index, but which takes into account the size of lesions; its value depended of course on clinical judgement in the selection of lesions.

It was desired to select those criteria which would divide patients as accurately as possible between groups with distinctly different 
TABLE 1

Skeleton Scheme of Classification

\begin{tabular}{|c|c|c|c|c|}
\hline \multirow{2}{*}{$\begin{array}{c}\text { General } \\
\text { Usage }\end{array}$} & \multirow{2}{*}{$\begin{array}{c}\text { Modified } \\
\text { Categories }\end{array}$} & \multicolumn{3}{|c|}{ Characteristics } \\
\hline & & $\begin{array}{l}\text { Clinical and } \\
\text { Histological }\end{array}$ & Bacilli* & Lepromin \\
\hline \multirow{2}{*}{ Tuberculoid } & (Tuberculoid TT & Full & Nil & Positive, 2 or $3+$ \\
\hline & $\begin{array}{l}\text { Borderline- } \\
\text { tuberculoid BT }\end{array}$ & $\begin{array}{l}\text { Near } \\
\text { tuberculoid }\end{array}$ & $\begin{array}{l}\text { Nil, } 1 \\
\text { or } 2+\end{array}$ & $\begin{array}{l}\text { Weak positive } \\
(1+) \text { or negative }\end{array}$ \\
\hline $\begin{array}{l}\text { Borderline } \\
\text { (Dimorphous) }\end{array}$ & Borderline ВВ & Borderline & 2 to $5+$ & Negative \\
\hline & $\begin{array}{l}\text { Borderline- } \\
\text { lepromatous BL }\end{array}$ & $\begin{array}{l}\text { Near lepro- } \\
\text { matous or } \\
\text { atypical }\end{array}$ & 4 or $5+$ & Negative \\
\hline & Lepromatous LL & $\begin{array}{l}\text { Full } \\
\text { lepromatous }\end{array}$ & 5 or $6+$ & Negative. \\
\hline Indeterminate & Indeterminate & $\begin{array}{l}\text { Not classifi- } \\
\text { able on TT- } \\
\text { LL scale. }\end{array}$ & Nil & $\begin{array}{l}\text { Weak positive or } \\
\text { negative. }\end{array}$ \\
\hline
\end{tabular}

* The bacterial indices here referred to are based on a logarithmic scale (Maximum $6+$ ) applied to skin smears.

The clinical and histological criteria of classification are given in the text.

TABLE 2

Clinical Criteria for Subdividing Borderline Leprosy

\begin{tabular}{|c|c|c|}
\hline Lesions & \multicolumn{2}{|c|}{ Type of Leprosy } \\
\hline Skin & $\begin{array}{l}\text { Borderline, nearer } \\
\text { lepromatous }(B L)\end{array}$ & $\begin{array}{l}\text { Borderline, nearer } \\
\text { tuberculoid }(B T)\end{array}$ \\
\hline Number & $\begin{array}{l}\text { Becoming more numer- } \\
\text { ous the nearer to lepro- } \\
\text { matous. }\end{array}$ & $\begin{array}{l}\text { Becoming less numerous } \\
\text { the nearer to tubercu- } \\
\text { loid. }\end{array}$ \\
\hline Size & Smaller on average. & Larger on average. \\
\hline Distribution & $\begin{array}{l}\text { Tendency towards bila- } \\
\text { teral symmetry. }\end{array}$ & Asymmetrical. \\
\hline Surface & $\begin{array}{l}\text { Smoother, shinier, more } \\
\text { hairy. }\end{array}$ & Rougher, drier, less hairy. \\
\hline $\begin{array}{l}\text { Pain, temperature } \\
\text { and touch sensa- } \\
\text { tion }\end{array}$ & Slight impairment. & $\begin{array}{l}\text { More pronounced impair- } \\
\text { ment. }\end{array}$ \\
\hline Thickened Nerves & & \\
\hline Number & More numerous. & Less numerous. \\
\hline Distribution & $\begin{array}{l}\text { Tendency to bilateral } \\
\text { symmetry. }\end{array}$ & Asymmetrical. \\
\hline
\end{tabular}


rates of fall in this bacteriological index in response to chemotherapy. From this point of view the clinical assessment of patients in the first trial was eminently successful; in one case classified as BT, 3 as $\mathrm{BB}, 10$ as $\mathrm{BL}$ and 21 as LL the mean fall in the biopsy index for each period of 6 months was BT $100 \%$, BB $96 \%$, BL $51 \%$ and LL $29 \%$. There was a very good demarcation of groups in terms of progress rates.

The histological criteria to be tested included the finding in significant numbers of Langhans's giant cells, epithelioid cells, histiocytes, foam cells, globi, foreign body giant cells, lymphocytes and plasma cells; and the presence of fibrosis, of a clear sub-epidermal zone, and of neural infiltration or perineural cuffing.

When an attempt was made to choose the criteria which would give the best differentiation of progress rates it was found that granulomata in which epithelioid cells were present gave a mean rate of fall in the index of $98 \%$; those in which epithelioid cells were absent but lymphocytes numerous gave a rate of $57 \%$, those in which foam cells and globi were the only prominent cells, $31 \%$. These figures are very close to those for the BB, BL and LL clinical groups. The other criteria which were considered proved to be of secondary importance and they are discussed later.

The same clinical and histological criteria were applied in the second trial at Sungei Buloh. The attempt to forecast clinically the rate of fall in the index under treatment was less successful than before; BB $70 \%$, BL $39 \%$, LL $33 \%$. There was nodefinite separation of BL and LL groups. To some extent this could be attributed to the fact that the second trial, unlike the first, was non-retrospective. To a greater extent it was probably due to the fact that the time available was insufficient for thorough clinical examinations.

Histologically the second trial necessitated some modification of the circumstances under which lymphocytes were to be considered as indicative of a BL classification (see below). When this revision was made the progress rates for the three categories were much the same as before: $89 \%, 58 \%$ and $33 \%$.

Histological classification. The mean progress rate for each of the histological criteria referred to above was calculated. After analysis of the results it was concluded that the typical features of the 5 groups were as follows. The descriptions refer to the fully developed lesions.

TT Focalized epithelioid cells, often with Langhans's giant cells, encompassed by zones of lymphocytes and extending up to the epidermis. Nerves within the granuloma infiltrated and often unrecognizable.

BT Epithelioid cells either focalized or accompanied by Langhans's giant cells or both. There is a narrow clear zone beneath the epidermis at least in some places. Lymphocytic infiltration 
sometimes heavy. Nerves often very swollen by infiltrate but usually they are discernible.

BB Diffuse epithelioid cell granuloma with little or no focalization and usually no Langhans`s giant cells. Lymphocytes variable. Usually some nerve damage and possibly cuffing or infiltration.

BL (1) Histiocytes showing a tendency to epithelioid cell development. Lymphocytes scanty.

(2) More commonly, histiocytes loaded with bacilli and perhaps some foamy degeneration but no large globi. Dense clumps of lymphocytes present $(a)$ as peri-neural cuffs or $(b)$ occupying whole segments of the granuloma.

LL Histiocytes typically show foamy degeneration and globus formation, but this may not exceed that of BL. Multinucleate globi, if present, are diagnostic. Lymphocytes diffuse or scanty especially in untreated cases.

The number of patients in the BT class with a sufficiently high index to justify follow-up was too low to be significant and in the TT class there was of course none. It was impossible therefore to assess the characteristics of these two classes separately in the followup study. The histological features referred to above are those which appeared to correlate best with the clinical findings, the lepromin test and the apparent stability of the patients.

The most striking correlation between bacteriological progress and a histological characteristic was in the case of the epithelioid cell. In 7 patients whose biopsies showed definite epithelioid cells the lowest fall in biopsy index in the first year of treatment was $88 \%$, the mean $96 \%$.

The main problem in the selection of patients for therapeutic trials was the definition of the BL and LL groups. In this matter the degree of cellular infiltration of the sub-epidermal zone was seldom helpful. Heavy infiltration was rare in LL cases but was also unusual in BL; minor degrees of infiltration showed no correlation with progress rates. Cellular infiltration of nerves was absent. Cuffing of small nerve trunks by lymphocytes however was a definite characteristic of the BL group. Damage to these nerves was of little significance; one presumed that it might have occurred during an earlier phase of the disease and the same applied to destruction of sweat glands. Silver impregnation of axons had some advantage over routine staining methods, but less for classification than for diagnosis. The presence of plasma cells or fibrosis had no correlation with rate of progress. Lymphocytes were significant either when present as peri-neural cuffs, or when they infiltrated densely an entire focus or segment of granuloma, in which case they were indicative of BL status. Diffuse relatively thin infiltration by lymphocytes, or clumps of these cells surrounded by foamy cells were quite consistent with 
LL classification, and lymphocytes could be numerous in ENL lesions. But lymphocytes were often the only histological indication that a patient was in the BL group; on occasion the decision between BL and LL could be difficult or impossible.

The BL group presents two alternative histological pictures according to whether the predominant cell is the lymphocyte or a degraded epithelioid cell. Lymphocytes are the predominant cell in early and indeterminate leprosy and it is possible that some of the BL cases in which lymphocytes predominate (and epithelioid cells are absent) are still in an early stage in the evolution of the infection. This type of case has been seen occasionally in Eurasians, Indians and Chinese, but it is most frequent and characteristic in some of the African races.

Giant multinucleate globi were indicative in all cases of the LL group.

Fat stains were carried out in some cases. We agree with DAvisOn, KoolJ and WAINWRIGHT (1960) that, although in general the more fat there is the nearer the lesion is to leproma, the test can be misleading in cases in which its help is most wanted. Its small value does not seem to justify the technical complication of undertaking fat stains for routine purposes.

Bacterial index. There is a broad correlation between the value of the bacterial index of smears (the density of bacilli in the granuloma) and the subsequent rate of fall in the biopsy index. The mean progress rates for the various indices were $2+, 97 \% ; 3+, 74 \%$; $4+, 81 \% ; 5+, 41 \% ; 6+, 30 \%$.

Discrepancies between clinical and histological findings. There was agreement on the exact classification of 56 out of the 82 cases. Minor disagreements usually concerned the decision whether a patient was to be classified BL or LL; in such cases the follow-up results usually supported the opinion in favour of LL unless the opposite opinion, whether clinical or histological, was unusually emphatic. There was serious disagreement as to whether the patient was BB or LL in 5 cases. Subsequent progress provided definite support for the clinical findings in 3 of them and for the histology in the other 2.

Occasionally the clinician diagnoses a borderline condition when the histology appears to be lepromatous, and often in such cases the clinical judgement is proved correct by the follow-up test of progress, but not invariably. Alonso and Azulay (1959) make the same comment. Sometimes the histological picture of these cases is masked by considerable oedema. As already stated, epithelioid cells when present are conclusive evidence of a considerable degree of resistance irrespective of the clinical findings.

In the final analysis a reasonably satisfactory classification was 


\section{TABle 3}

Final classification of 82 cases according to clinical and histological assessments, and their progress rates.

\begin{tabular}{|c|c|c|c|c|c|c|c|c|c|c|c|c|c|c|c|}
\hline \multirow{2}{*}{$\begin{array}{l}\text { Assessment: } \\
\begin{array}{c}\text { Clini- Histolo- } \\
\text { ical }\end{array} \quad \text { gical }\end{array}$} & \multirow{2}{*}{$\begin{array}{c}\text { Final } \\
\begin{array}{c}\text { Classifica- } \\
\text { tion }\end{array}\end{array}$} & \multicolumn{10}{|c|}{$\begin{array}{c}\% \text { Fall in Biopsy Index per } 6 \text { months treatment } \\
\text { Number of Cases }\end{array}$} & \multirow{2}{*}{\multicolumn{2}{|c|}{$\begin{array}{l}\text { Total } \\
\text { No. of } \\
\text { Cases }\end{array}$}} & \multirow{2}{*}{\multicolumn{2}{|c|}{$\begin{array}{l}\text { Mean \% } \\
\text { Progress } \\
\text { Rate per } \\
6 \text { months }\end{array}$}} \\
\hline & & $\begin{array}{l}0- \\
9 \%\end{array}$ & $\begin{array}{l}10- \\
19 \%\end{array}$ & $\begin{array}{l}20- \\
29 \%\end{array}$ & $\begin{array}{l}30- \\
39 \%\end{array}$ & $\begin{array}{l}40- \\
49 \%\end{array}$ & $\begin{array}{l}50- \\
59 \%\end{array}$ & $\begin{array}{l}60- \\
69 \%\end{array}$ & $\begin{array}{l}70- \\
79 \%\end{array}$ & $\begin{array}{l}80- \\
89 \%\end{array}$ & $\stackrel{90-}{100 \%}$ & & & & \\
\hline $\begin{array}{l}\mathrm{LL}-\mathrm{LL} \\
\mathrm{LL}-\mathrm{BL} \\
\mathrm{BL}-\mathrm{LL}\end{array}$ & LL & 2 & 9 & 15 & 17 & 9 & 2 & 0 & 0 & 0 & 0 & $\left.\begin{array}{r}41 \\
5 \\
8\end{array}\right)$ & 54 & $\left.\begin{array}{l}28 \\
30 \\
33\end{array}\right)$ & $30 \%$ \\
\hline $\begin{array}{l}B L-B L \\
B B-B L\end{array}$ & $\mathrm{BL}$ & 0 & 0 & 2 & 2 & 0 & 4 & 2 & 3 & 2 & 2 & $\left.\begin{array}{r}10 \\
7\end{array}\right\}$ & 17 & $\left.\begin{array}{l}60 \\
66\end{array}\right\}$ & $64 \%$ \\
\hline $\begin{array}{l}\mathrm{L} L-B B \\
B L-B B \\
B B-B B\end{array}$ & BB & 0 & 0 & 0 & 0 & 0 & 0 & 0 & 0 & 1 & 5 & $\left.\begin{array}{l}1 \\
0 \\
5\end{array}\right)$ & 6 & $\left.\frac{93}{96}\right)$ & $95 \%$ \\
\hline $\mathrm{BB}-\mathrm{LL}$ & $?$ & 0 & 1 & 0 & 0 & 0 & 0 & 0 & 2 & 0 & 1 & 4 & & - & \\
\hline
\end{tabular}


obtained for 78 out of the 82 cases, as shown in Table 3, which also records their progress rates.

Reactions. Cases with severe reactions have been excluded from this analysis at the time of the reaction and subsequently; figures therefore cannot be quoted. But our experience is that, although the borderline state is well recognized to be unstable when untreated, with treatment the great majority of cases respond predictably without alteration of classification, although on occasion alterations occur as a result of reactions. Cases undergoing a borderline reaction tend to show discrepancies between their clinical, histological and bacteriological patterns fairly frequently.

BL cases appear to be suitable for therapeutic trials, although their rate of progress is less predictable than that of $\mathrm{BB}$ or LL cases. Occasionally they react, and move to BB, even though their previous progress may have been slow. They differ from LL cases in that erythema nodosum leprosum never occurs in them.

Racial differences. The available results suggest that there are no differences in rate of bacteriological improvement for any particular category (BB, BL or LL) among Europeans, Eurasians, Negroes, Indians, Malayans and Chinese. The only differences detected concern the distribution of cases between the classification groups, to which reference has already been made.

\section{Discussion}

The application of a classification such as the one described will be strictly limited. There is however nothing incompatible between a strictly defined scheme of classification and a looser and simpler classification which would be of more general use-all that is required is that there should be available a loose and flexible terminology such as the one in current use besides another more strictly defined set of terms such as the TT-LL grouping (Table 1). The definition of criteria would be the same for both sets of terms. But whereas classification in the field would be mainly clinical and would employ the general terminology, a classification based on clinical, histological and other evidence would employ the precise terminology.

There is however little hope that agreement would be reached on the definition of groups unless there was prior agreement on the object of classification. If, because clinical examination is the most feasible means, the object is to be clinical description, then there will need to be as many groups as there are clinical varieties of patient; but their significance will be in doubt. If the object is to assess the patient's resistance and prognosis by reference to all observable characteristics then the matter can be put to the test. 


\section{Summary}

The paper attempts to define a 5 group classification of leprosy in which the groups represent 5 grades of resistance by patient to infection.

The definition was made by assessing the significance of clinical, histological and other characteristics by reference to the bacteriological response to treatment.

\section{Acknowledgements}

Our thanks are due to the physicians of the Hospital for Tropical Diseases, London, and of the Sungei Buloh Settlement, Malaya, for their co-operation and permission to report on their patients; to Dr. J. A. McFadzean and Dr. M. F. R. Waters of the Research Unit, Sungei Buloh, for sending us biopsy specimens, and to Miss Marian Wise for their histological preparation; and to Dr. R. J. W. Rees for some helpful criticisms.

\section{References}

Alonso, A. M. and Azulay, R. D. (1959) Int. Journ. Lep. 27, 193.

Davison, A. R., Koolu, R. and Wainwright, J. (1960) Ibid, 28, 126.

RIDLEY, D. S. (1958) Leprosy Rev. 29, 45. 